\title{
Design Algorithm of a Free Surface Water Tunnel to Test the Surface- Piercing Propellers (SPP); Case Study Water Tunnel of Babol Noshirvani University of Technology
}

\author{
Seyyed Mostafa Seyyedi ${ }^{1}$, Rouzbeh Shafaghat ${ }^{2 *}$ \\ ${ }^{1}$ PhD Student, Babol University of Tech.; Sea Based Energy Research Group, Mostafa_5054@yahoo.com \\ ${ }^{2}$ Assistant Prof., Babol University of Tech.; Sea Based Energy Research Group, rshafaghat@nit.ac.ir
}

\begin{tabular}{|c|c|}
\hline ARTICLE INFO & ABSTRACT \\
\hline $\begin{array}{l}\text { Article History: } \\
\text { Received: } 28 \text { jun. } 2016 \\
\text { Accepted: } 7 \text { Aug. } 2016\end{array}$ & $\begin{array}{l}\text { Surface-Piercing Propellers (SPPs) have been widely used in high speed craft } \\
\text { due to some desirable features such as high efficiency, omission of resistance } \\
\text { of equipment attached to the propeller and proper functioning of cavitation. }\end{array}$ \\
\hline $\begin{array}{l}\text { Keywords: } \\
\text { Free surface water tunnel } \\
\text { Surface-piercing propeller } \\
\text { Experimental test }\end{array}$ & $\begin{array}{l}\text { application on simulation of SPPsbecause of problems related to modeling of } \\
\text { these propellers. Design of SPPs is mainly done based on empirical studies } \\
\text { and model experiments. Water tunnel or free surface cavitation tunnel is } \\
\text { among the most important devices to perform SPPs model testing. In this } \\
\text { paper, the design algorithm of a free surface water tunnel to test the SPPs has } \\
\text { been described. The design and construction stages of the free surface } \\
\text { cavitation tunnel of Babol Noshirvani University of Technology are } \\
\text { provided. Also,calculation of its various sectors such as elbows, nozzle, } \\
\text { settling chamber, test section, diffuser and calculation of pressure drops, } \\
\text { proper pump selection and dynamometer has been showed. }\end{array}$ \\
\hline
\end{tabular}

\section{Introduction}

The first patent license for SPPs was conducted by David Napier in 1841 [1]. According to Hadler and Hecker [2], another patent on SPPs goes back to 1869 in Philadelphia, U.S. since then, this type of propellers were gradually used at hydroplanes and racing speed boats [3]. Today, commercial marine industries have shown a growing tendency to use SPPs for high speeds in the range of 70 to 80 knots [4]. Due to the distance of these types of propellers to the body, they have no restrictions to be used in shallow waters, and in fact, they are a type of propulsion systems suitable for fast vessels [5]. The use of SPPs in propulsion systems decreases the axial angle. Given the fact that up to $30 \%$ of the total vessels' resistance is consisted of propulsion system resistance [6], it leads to increased thrust, increased efficiency, and thus, saving in fuel consumption.

Generally, for propellers modeling and hydrodynamic phenomena, there are three general methods of mathematical modeling, numerical modeling and experimental modeling. The safest method is to use experimental modeling and testing. Its only error is the measurement error and accurate method of testing. In SSPs, unlike submerged propellers, theoretical methods do not have significant application because of difficulties and complexities of modeling of these propellers due to working in the liquid and air interfaces. The design of SPPs is mainly done based on empirical studies, experimental modeling and model testing [7]. Given the importance of doing model testing for SPPs, different laboratory facilities are defined and provided. Water or cavitation tunnel is one of the most important instruments for performing propellers experimental tests, which is used nowadays as a very efficient and useful tool to study and investigate hydrodynamic phenomena. Measuring hydrodynamic forces on underwater objects as well as hydrodynamic forces of hydrofoils and propellers are one of the basic functions of water tunnel [8]. In recent years, because of the low volume (compared to the towing tank), low cost and results assessment in very short time, the water tunnel test has been very useful. Water tunnels are generally classified from three perspectives of maximum fluid speed in the test section, type of testing section and fluid flow circuit. In tunnels classification based on type of test section, open jet, free jet, closed jet, fractured walls and the free surface tunnels can be mentioned. To study the flow around objects in case of occurring on the free surface or near it, the free surface water tunnels are used (Figure 1). In this category of tunnels, the water 
flow is limited by solid boundaries in the lower and lateral sections, and the upper part lacks solid border; in fact, this border is the interface of air and water. This tunnel is used to study the hydrofoils and SPPs.

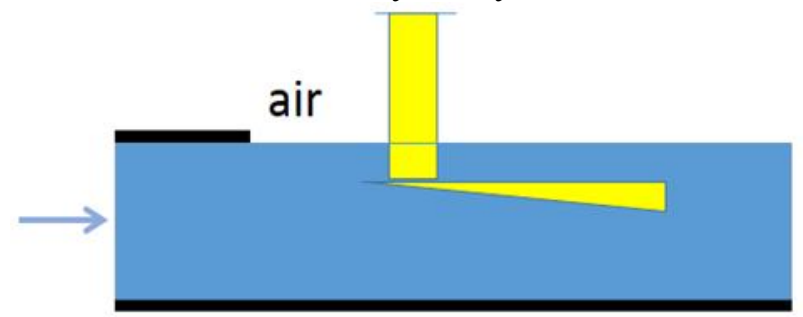

Figure 1. Schematic of free surface test section

According to the capabilities required to test the SPPs, the water tunnel built in the Sea-based Energy Research Group of Babol Noshirvani University of Technology, is a free surface water tunnel. In Table 1, the characteristics of a number of free surface water tunnels built in the world are listed.

Table 1. The characteristics of a number of free surface water tunnels built in the world

\begin{tabular}{|c|c|c|c|c|}
\hline \multicolumn{2}{|c|}{ Name of tunnel } & $\begin{array}{c}\text { Cavitation } \\
\text { tunnel K27 } \\
\text { (Germany) } \\
{[9]}\end{array}$ & $\begin{array}{c}\text { Cavitation } \\
\text { tunnel of } \\
\text { university of } \\
\text { Tasmania } \\
{[10]}\end{array}$ & $\begin{array}{c}\text { Cavitation } \\
\text { tunnel of } \\
\text { university of } \\
\text { Rostock } \\
{[11]} \\
\end{array}$ \\
\hline \multicolumn{2}{|c|}{ Type of test ection } & Free surface & Free surface & Free surface \\
\hline \multirow{3}{*}{$\begin{array}{l}\text { Test section } \\
{[\mathrm{m}]}\end{array}$} & Length & 0.6 & 0.6 & 0.6 \\
\hline & Width & 0.6 & 0.6 & 0.3 \\
\hline & Height & 3.75 & 2.6 & 0.6 \\
\hline \multicolumn{2}{|c|}{$\begin{array}{l}\text { Maximum velocity in test } \\
\text { section }[\mathrm{m} / \mathrm{s}]\end{array}$} & 14 & 12 & 7 \\
\hline \multirow{2}{*}{$\begin{array}{l}\text { Tunnel } \\
\text { dimensions } \\
\text { [m] }\end{array}$} & Length & 27.3 & --- & --- \\
\hline & Height & 8.4 & ---- & 1.8 \\
\hline \multirow{2}{*}{ Generator } & RPM & 1800 & ---- & 1920 \\
\hline & {$[\mathrm{kw}]$} & 600 & 200 & 15 \\
\hline
\end{tabular}

General schematic of the closed circuit surface water tunnel built in the Babol Noshirvani University of Technology are shown in Figure 2. In this paper, the general algorithm of design of the free surface water tunnel and its processes have been described. After calculating and determining the conditions needed to test a SPP in the test section, the stages of design and construction of each of the components of the free surface cavitation tunnel of the Sea-based Energy Research Group, how to calculate the thickness of the boundary layer in the testing section, pressure drop, forces acting on the components and choosing the right pump are provided.

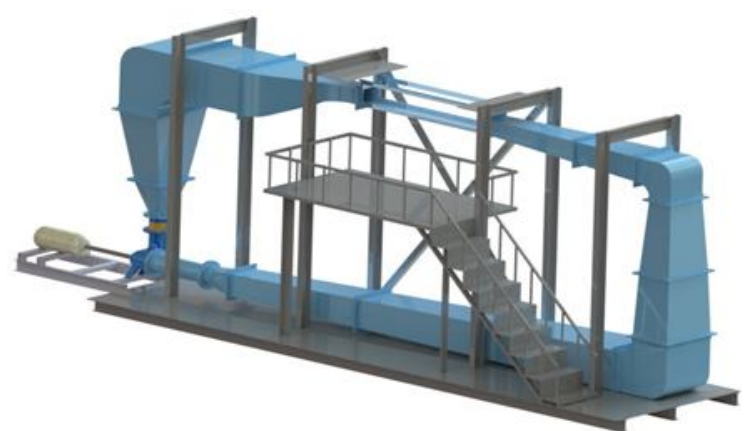

Figure 2. General schematic of the closed circuit free surface water tunnel of the Babol Noshirvani University of Technology

\section{General algorithm of designing the free surface water tunnel}

The aim of the design and construction of surface water tunnel is to provide conditions needed for doing the test in the test section. Therefore, conditions and parameters needed for testing the SPP in the test section were first identified. Then, with that in mind, the maximum speed, test section dimensions, dimensions and profile of the nozzle, elbow dimensions and number of blades, honeycomb, diffuser's size, tunnel drop and pump needed were determined.

The general algorithm of designing the free surface water tunnel to test the SPP is shown in Figure 3.

\subsection{Determining the maximum advance ratio and profile of the SPP under test}

According to modeling from the tests conducted in the past, the diameter of the propeller impeller occurs in the range of 100-300 (mm) [12-16]; therefore, in this design, the propeller diameter model as an important proviso was selected as $120(\mathrm{~mm})$. Due to the satisfaction of the dimensionless numbers of Reynolds, Froude and Weber and using the specified range, the dimensionless number of the advance coefficient is used to generalize the results from the model to the original sample. In most conducted tests, the followings were considered:

- Advance coefficient range: 0.3-1.2

- Immersion ratio: 0.3-0.8

- Shaft inclination angle range: 0 to 15 degrees

- Expanded area ratio range: 0.4-0.9 


\section{Start}

1

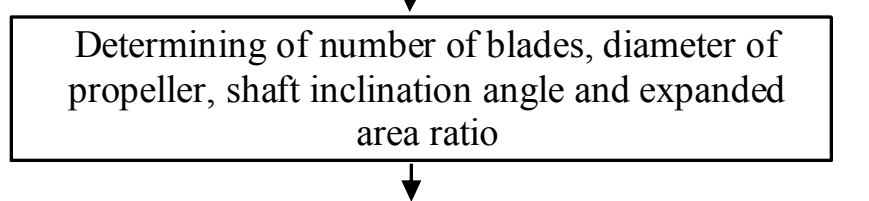

Determining minimum RPM needed to test the model propeller

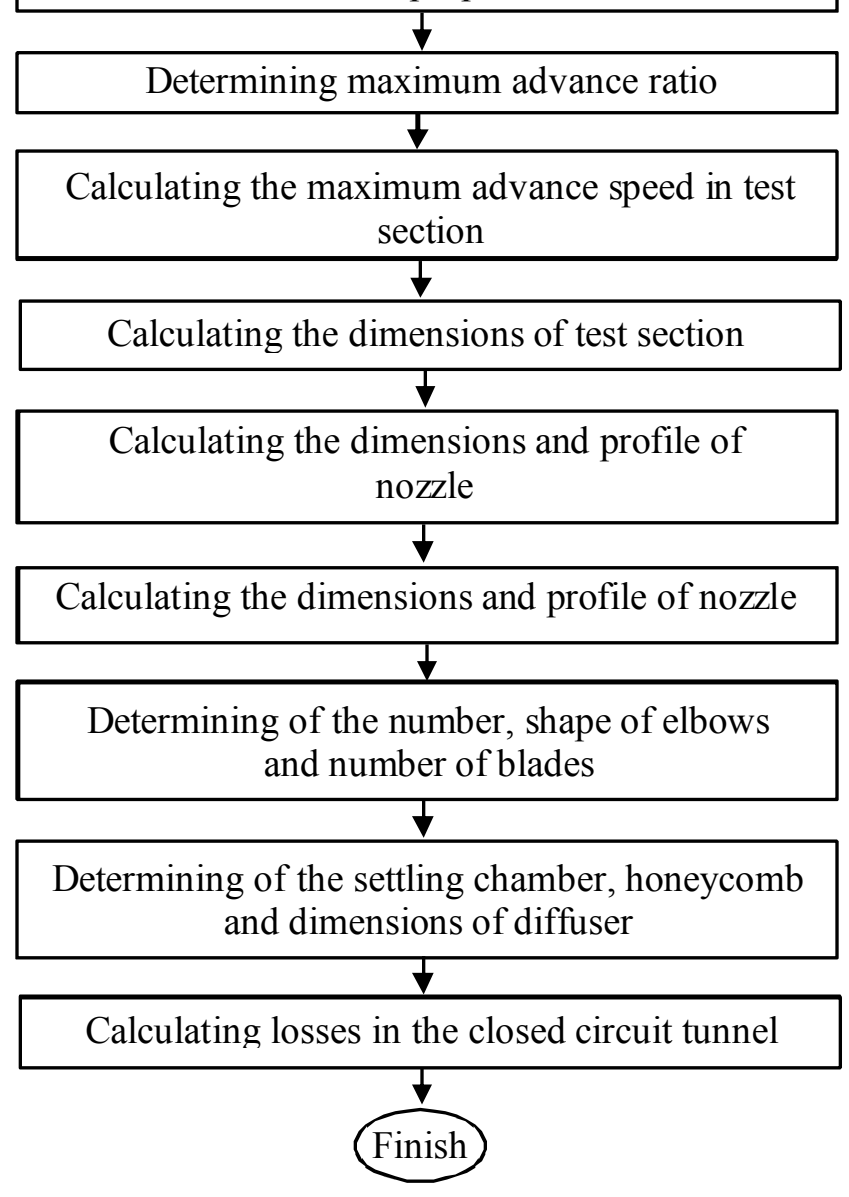

Figure 3. General algorithm of designing the free surface water tunnel

In this work, the maximum advance ratio is equal to 1. For a basic premise and criteria, the number of blades is 4 , shaft inclination angle equals to 15 degrees, and the expanded area ratio range is assumed as 0.58 .

\subsection{Minimum RPM needed to test the model propeller}

The most important parameters affecting the behavior of SPPs include geometric features, such as the number of blades, pitch ratio, expanded area ratio, Rake angle, blade section as well as physical working conditions, including immersion ratio, advance coefficient, Reynolds number, cavitation number, Weber number, shaft angle and Froude number. In addition to these parameters, the parameters of Yaw angle and Skew angle are as another important factors affecting the SPPs performance. In general, parameters affecting the thrust and torque hydrodynamic coefficients for SPPs are defined as a function according to equation (1):

$$
K=f\left(\begin{array}{l}
Z, \frac{P}{D}, \frac{A_{E}}{A_{o}}, f, t, \theta_{r}, \theta_{s}, J, \\
I_{T}, \Psi, \gamma, \sigma, \mathrm{Re}, F r, W e
\end{array}\right)
$$

Among these parameters, the dimensionless numbers of cavitation, Froude, Weber and Reynolds are included in the limitations and selection conditions. Once they are satisfied, other parameters would have a major role in the hydrodynamic coefficients values [5].

Similarity laws must be established to test the SPP in the cavitation tunnel and generalize the model results to an actual sample of the SPP. In the SPPs, the similarity laws cannot be established for dimensionless numbers of Weber, Froude and Reynolds. One of the problems in testing the surfacepiercing propeller model is to determine the range of the Weber and Froude numbers. A common way to generalize the results from model to the original sample, which has been used in 2007 at the Krylov Ship-building Research Institute (KSRI), Russia to design a series of SPPs, is to set ranges for Reynolds, Froude and Weber numbers [4]. Establishing the following conditions, the curve of the surface-piercing propeller performance would be independent of the above dimensionless numbers:

$$
\begin{aligned}
\mathrm{Re}_{n} & =\frac{n \times D^{2} \times\left(A_{E} / A_{o}\right)}{v \times Z} \geq 5 \times 10^{5}, \\
W_{n} & =\sqrt{\frac{\rho \times n^{2} \times D^{3}}{\sigma}} \geq 180, \\
F r & =n \sqrt{\frac{D}{g}} \geq 3.5
\end{aligned}
$$

Using equation (2), the minimum RPM requirement is determined to test the propeller model. Due to assumptions, its value will be obtained as 38.32 (rps) or 2300 (RPM).

\subsection{Maximum advance speed}

Using the equation $J=\frac{V_{A} \times \cos (\Psi)}{n \times D}$, the maximum advance speed is achieved; where:

$\Psi$ : Shaft angle of deflection

$\mathrm{n}$ : Minimum rpm required

$D$ : Propeller diameter

Thus, considering the conditions required to test for the SPP, the maximum speed required in the test section is obtained as $5(\mathrm{~m} / \mathrm{s})$. In Table 2 , the required speed corresponding to the advance coefficient to test the SPP, with the expanded area ratio of 0.58 , diameter of $0.12(\mathrm{~m}), 4$ blades and 15 degrees deflection of the shaft angle are given. 
Table 2. The required speed with the rate of advance coefficient to test of surface-piercing propeller with pitch ratio of 0.58, 4-blade and shaft inclination angle of 15 degrees

\begin{tabular}{lcccc}
\hline Minimum rpm & 2300 & 2300 & 2300 & 2300 \\
\hline Advance coefficient & 0.21 & 0.52 & 0.84 & 1 \\
\hline Advance velocity [m] & 1 & 2.5 & 4 & 5.05 \\
\hline
\end{tabular}

\subsection{Hydrodynamic design of the test section}

The most important component of any water tunnel to start the design process is the testing part (model installation site). In the test section, flow conditions ranging from good stability, uniformity and lack of annoying disturbances should be established to achieve accurate and acceptable results. The test section size limits and defines the size of model to be tested within it. It should be noted that the effects of tunnels and walls have a direct impact on the size of the model [17]. The main characteristics defining the water tunnel testing section are:

- Transverse cross section

- Cross section shape

- Length

- Speed

- Flow uniformity and stability

Determining the maximum speed of the test section and dimensions of the model propeller, the dimensions of the test section can be determined. To determine the size of the test section, the factors of flow rate, central axis speed change, the boundary layer growth, blockage ratio, available length and its cost should be considered. Through modeling the free surface tunnels made and consideration of their blockage ratio (ratio of model area to the section area of the test), the dimensions of the rectangular test section in the free surface tunnel built, are shown in Table 3. Also in Figure 4, the test section made for the water tunnel is shown.

Table 3. Specifications of test section in the free surface tunnel built

\begin{tabular}{ccc}
\hline Length $[\mathrm{m}]$ & Width $[\mathbf{m}]$ & Height $[\mathbf{m}]$ \\
\hline 0.2 & 0.3 & 2 \\
\hline
\end{tabular}

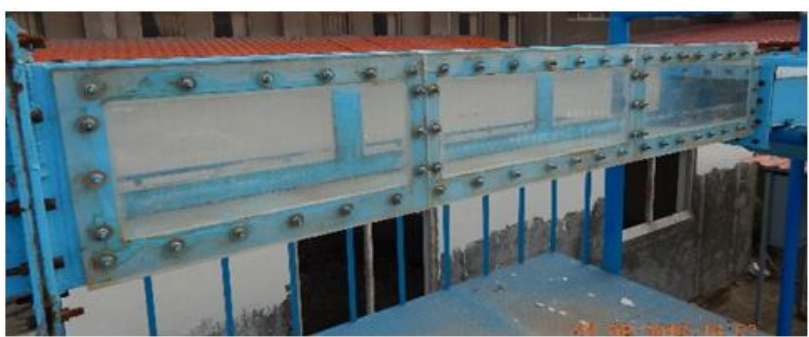

Figure 4. Test section of water tunnel of Babol Noshirvani unversity of Technology

\subsubsection{Boundary layer growth and blockage ratio in the test section}

One of the important issues in the design of the test section is to evaluate the effect of boundary layer growth on the results of tests in the test section. It is obvious that the maximum thickness of the boundary layer in the test section should be small compared to the distance between the confronting surfaces. Also, the flow surrounding test model needs to be away from the wall viscosity effects in a suitable distance from the boundary layer.

After calculating the dimensions of the test section, the properties of water at $20{ }^{\circ} \mathrm{C}$ are used to calculate the thickness of the boundary layer in the test section. The first step is to determine the type of flow regime within the test section (laminar or turbulent). To this end, through calculating the Reynolds number from equation (3), the type of flow regime will be specified.

$$
\begin{aligned}
& D=\frac{4 A}{p}=\frac{4 \times 0.3 \times 0.2}{2(0.3+0.2)}=0.24, \\
& \operatorname{Re}_{D}=\frac{V \times D}{v}=\frac{V \times 0.24}{1.007 \times 10^{-6}} \Rightarrow \operatorname{Re}_{D \min }=2.4 \times 10^{5}
\end{aligned}
$$

where:

$A$ : Cross-section area of test section

$p$ : Perimeter

$D$ : Hydraulic radius

\section{$V$ : Advance velocity}

Due to the condition of turbulent of $\operatorname{Re}>4000$ and given the minimum Reynolds number in the test section obtained by the rate of $1(\mathrm{~m} / \mathrm{s})$, the flow is quite turbulent. It should be noted that in case of using the turbulent measure on a flat plane $(\operatorname{Re}>500000)$, the flow will be turbulent as well. In the turbulent flow, the boundary layer thickness on the plane is calculated from equation (4) that the maximum boundary layer occurs at the end of the test section.

$\delta=\frac{0.37 \times L}{\operatorname{Re}_{l}^{0.2}}$

Drawing the thickness of the boundary layer for test chamber with a length of $2(\mathrm{~m})$ and different speeds of 1 to $5(\mathrm{~m} / \mathrm{s})$, a diagram is obtained as shown in Figure (5). 


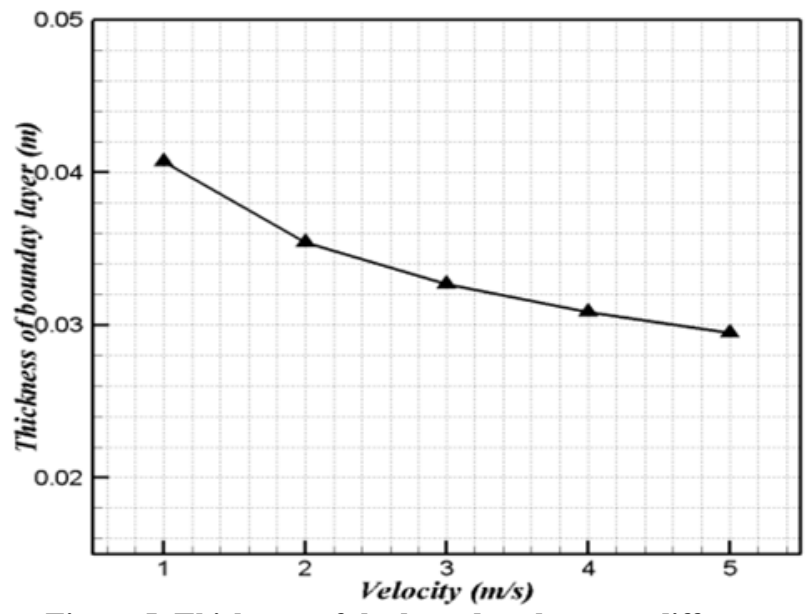

Figure 5. Thickness of the boundary layer on different velocity

Considering the length of $2(\mathrm{~m})$ for the test chamber and a speed of at least $1(\mathrm{~m} / \mathrm{s})$, the thickness of the boundary layer at the end of the test section where the maximum thickness of the boundary layer occurs would be obtained as $0.04(\mathrm{~m})$, which is shown in Figure (6).

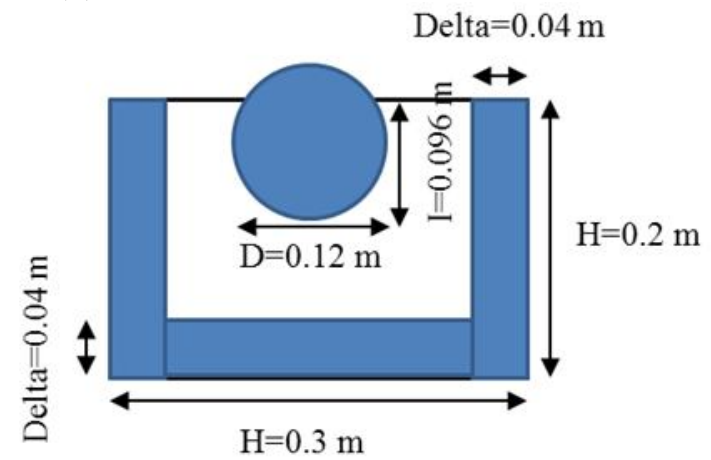

Figure 6. Thickness of the boundary layer at the end of the test section

The standard amount of blockage ratio in the design of the test section is equal to $15 \%$, which usually ranges between $10 \%$ and $16 \%$ [18]. Through modeling the free surface tunnels made and maximum propeller diameter for testing, it was found that the value of blockage ratio is also considered up to $24 \%$. In this study, considering the immersion ratios of $80 \%$ and $30 \%$, the blockage ratio values were obtained using equation (5) as $15 \%$ and $5.6 \%$, respectively.

$$
B=\frac{A_{\text {Blockage }}}{A_{T . S}}
$$

According to the topics mentioned above, the main parameters of the water tunnel test section can be summarized in Table 4:
Table 4. The main parameters of the water tunnel test section

\begin{tabular}{cc}
\hline Parameter of design & Result \\
\hline Type of test section & Free surface \\
\hline Shaped of test section & Rectangular \\
\hline $\begin{array}{c}\text { Size of test section } \\
\text { (length, width, height) [m] }\end{array}$ & $2,0.3,0.2$ \\
\hline Maximum velocity on test section [m/s] & 5 \\
\hline $\begin{array}{c}\text { Maximum growth of the boundary } \\
\text { layer in the test section [mm] }\end{array}$ & 40.7 \\
\hline
\end{tabular}

\subsection{Hydrodynamic design of the nozzle}

The growth of the boundary layer on the path leading to the test section is one of the main factors of profile non-uniformity of the fluid velocity in the test section. Therefore, reducing the thickness of the boundary layer is very effective in improving the profile uniformity of the fluid velocity. In general, we need a part called nozzle in the water tunnels to do the tasks of accelerating the flow, providing profile uniformity of the fluid velocity and reduction of the input current turbulences into the test section. Figure 7 shows the uniformity created in the nozzle outlet flow.

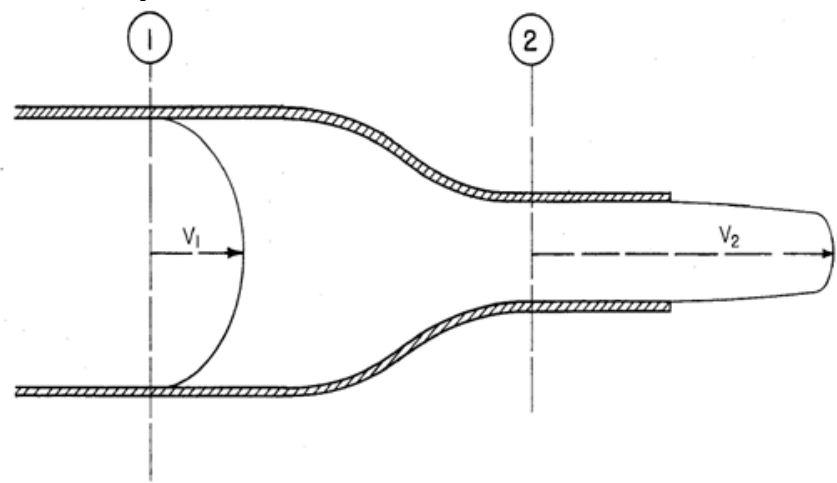

Figure 7. Uniformity created in the nozzle outlet flow [17]

In the event of intense adverse pressure gradient at the inlet and outlet sections of the nozzle, the separation of the boundary layer at these two sections of the nozzle would be likely, which causes instability, loss of quality in the test section, increased drops, and consequently increased costs. Adverse pressure gradient at the entrance arises from the fact that the fluid velocity slightly decreases at the entrance to the nozzle at the beginning, and then starts to increase. With increasing the nozzle length, which causes the uniform change of the section area, the occurrence of the adverse pressure gradient can be prevented. Also, increasing the nozzle length causes the thickness of the boundary layer, which is undesirable. Given the above, an optimal length should be used to create favorable conditions. The basic parameters in designing the nozzle include: Contraction ratio, length, uniformity profile of the nozzle speed. Generally, the nozzle design methodology is described in the following figure: 
Determining of convergence ratio according to existing standards

Determining of convergence ratio according to existing standards

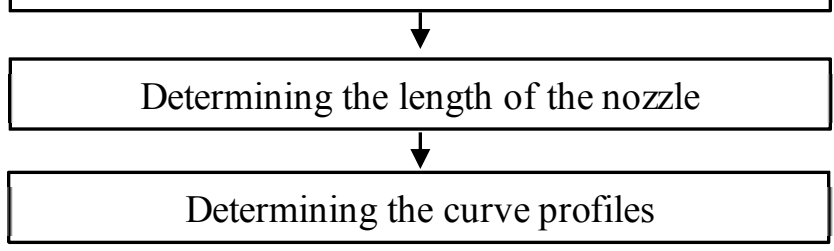

Figure 8. Design methodology of the nozzle

The nozzle section shape in each water tunnel is a function of the section shape of other parts of the tunnel. Since the present water tunnel test section is rectangular, the nozzle section shape is also selected rectangular. It should be noted that since the present tunnel is a tunnel with a free surface test section, its nozzle would an asymmetric one, and calculations of other parameters must be made based on the dimensions of a symmetrical nozzle.

Research suggests that for $1 \%$ deviation from the flow uniformity, the most appropriate convergence ratio seems to be about 9 to 1 . According to the information on water tunnels in the world, the contraction ratio of 9 to 1 is used for the studied water tunnel. Generally, nozzles with symmetrical design and an area ratio of 9 to 1 have high efficiency and low turbulence. In selecting the nozzle length due to information of cavitation tunnels in the world, the ratio of length to the output height was selected as 4 (The nozzle length is 3.5 to 5 times of the outlet height of that nozzle).

One of the methods for calculating the nozzle profile is Bell and Mehta methodology. These researchers [19] believe that the use of a curve with a derivative of zero in the inlet and outlet areas of the nozzle can meet a uniform flow, low boundary layer satisfy and insignificant loss. They suggested the following general equation for the nozzle profile.

$$
\begin{aligned}
\mathrm{h}(\mathrm{X}) & =\left[\left(\mathrm{H}_{\mathrm{o}}^{1 / a}-\mathrm{H}_{\mathrm{i}}^{1 / a}\right)\right. \\
& \left.\times\left[6 \mathrm{X}^{5}-15 \mathrm{X}^{4}+10 \mathrm{X}^{3}\right]+\mathrm{H}_{\mathrm{i}}^{1 / a}\right]^{\mathrm{a}}
\end{aligned}
$$

Where $\mathrm{X}=\mathrm{x} / \mathrm{L}$, $\mathrm{x}$ Nozzle length coordinates, L Nozzle length, $h$ Height of the nozzle at any point $x$, $\mathrm{H}_{\mathrm{i}}$ Nozzle inlet height, $\mathrm{H}_{\mathrm{o}}$ Nozzle outlet height, a An additional variable to increase the number of possible modes. Reasonable amount of "a" is obtained depending on the type of problem and through evaluating the curves obtained at different values of "a".

In the studied project, according to the output conditions (test section), contraction ratio of 1 to 9 and the output length/height of 4 (The nozzle length is
3.5 to 5 times of the outlet height of that nozzle), the tunnel length would be obtained as $\mathrm{L}=1.6(\mathrm{~m})$. Assuming the symmetrical nozzle, the profile equation would be as equation (7).

$$
\begin{aligned}
\mathrm{h}(\mathrm{X}) & =\left[\left(0.15^{1 / a}-0.45^{1 / a}\right)\right. \\
& \left.\times\left[6 \mathrm{X}^{5}-15 \mathrm{X}^{4}+10 \mathrm{X}^{3}\right]+0.45^{1 / a}\right]^{\mathrm{a}}
\end{aligned}
$$

In the final stage, by drawing different values of "a" in figure (9), it can be seen the nozzle profiles overlap each other from values of $a>8$. With regard to this issue, the value of "a" has been considered in the project as $\mathrm{a}=8$.

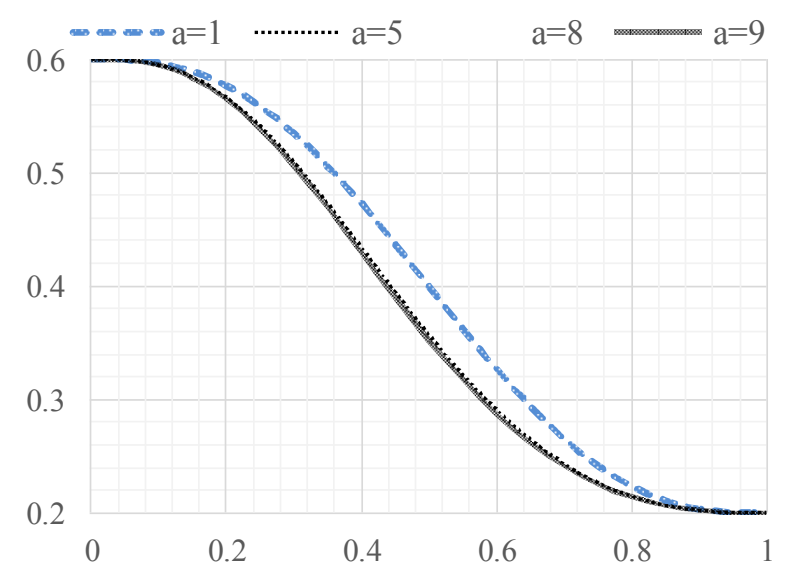

Figure 9. Difference between nozzle profile for different amount of "a"

Finally, the nozzle profile equation would be as equation (8), by drawing which, Figure (10) will be obtained. Finally, the nozzle profile equation would be as equation (8), by drawing which, Figure (10) will be obtained.

$$
\begin{aligned}
& h(X)=\left[\left(0.15^{0.125}-0.45^{0.125}\right)\right. \\
& \left.\times\left[6 X^{5}-15 X^{4}+10 X^{3}\right]+0.45^{0.125}\right]^{8}
\end{aligned}
$$

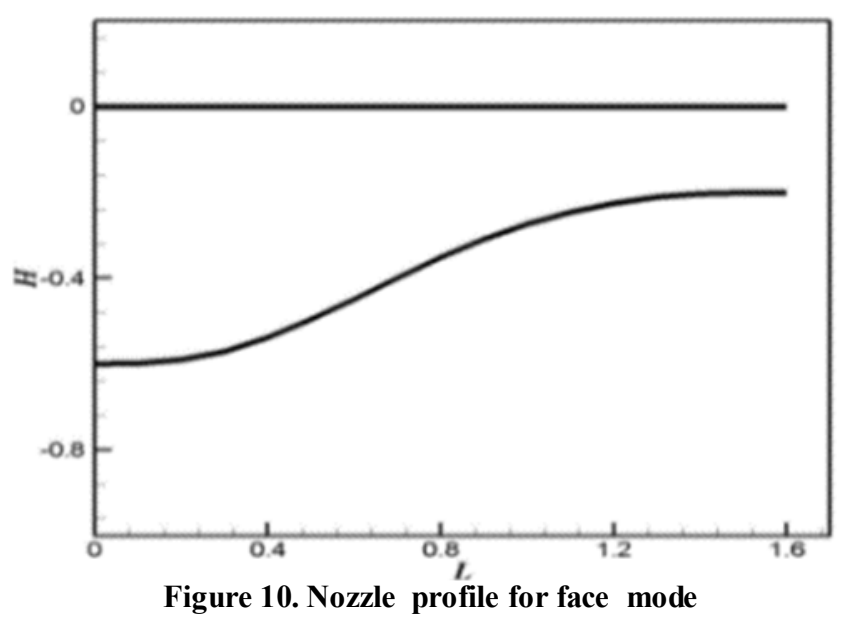

Doing the calculations and given the non-symmetric nozzle, its size and shape in the tunnel made are shown respectively in Table 5 and Figure (11). 
Table 5. Dimensions of asymmetric nozzle of the free surface tunnel built

\begin{tabular}{ccccc}
\hline $\begin{array}{c}\text { Length } \\
{[\mathrm{m}]}\end{array}$ & \multicolumn{2}{c}{ Inlet } & \multicolumn{2}{c}{ Outlet } \\
\cline { 2 - 5 } & $\begin{array}{c}\text { Height } \\
{[\mathbf{m}]}\end{array}$ & $\begin{array}{c}\text { Width } \\
{[\mathbf{m}]}\end{array}$ & $\begin{array}{c}\text { Height } \\
{[\mathbf{m}]}\end{array}$ & $\begin{array}{c}\text { Width } \\
{[\mathbf{m}]}\end{array}$ \\
\hline 1.6 & 0.6 & 0.9 & 0.2 & 0.3 \\
\hline
\end{tabular}
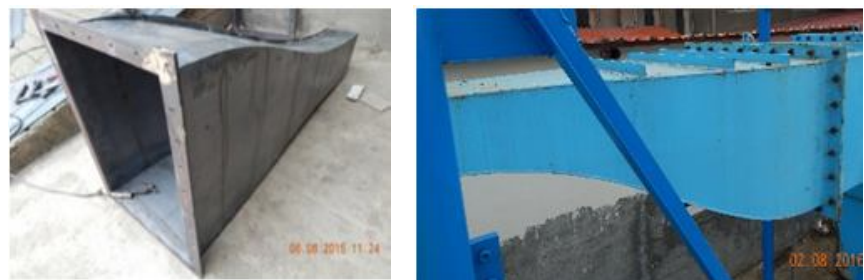

Figure 11. Nozzle of water tunnel of Babol Noshirvani unversity of Technology

\subsection{Hydrodynamic design of the diffuser}

Diffuser consists of a divergent channel that occurs after the water tunnel test section, and the water flow enters it after passing the test section. In the water tunnel, a diffuser is used to reduce the output flow rate of the test section and increase the flow pressure. This will eventually lead to reduced power required for circulating water flowing in the tunnel.

The performance and overall geometry of the diffuser are shown in Figure (12).
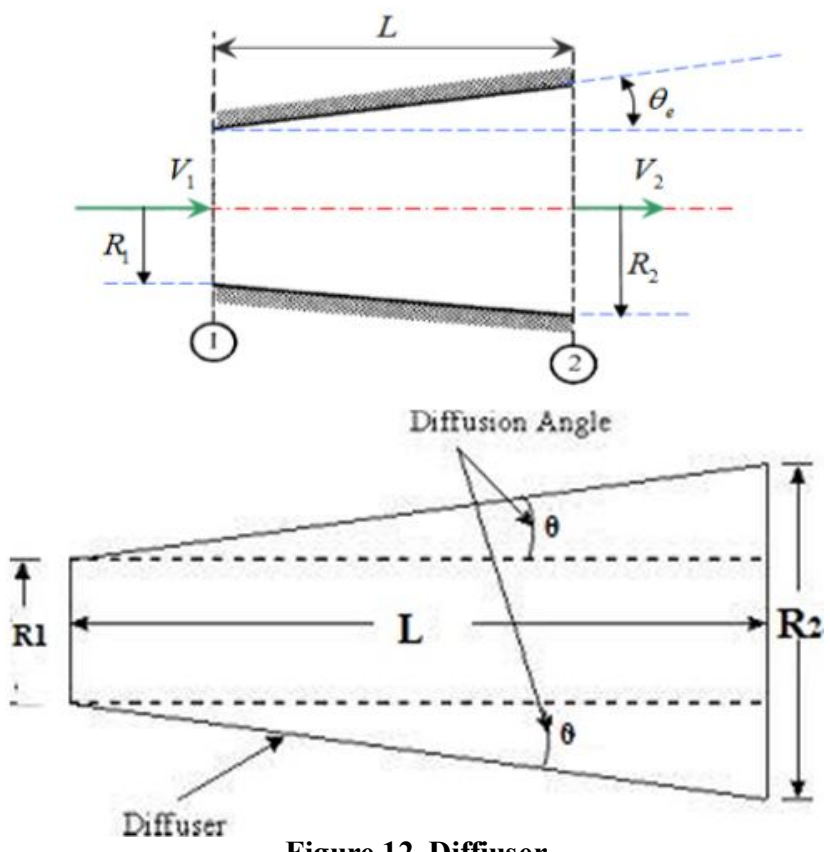

Figure 12. Diffiuser

Unlike the nozzle, there is an adverse pressure gradient in the diffuser that may cause the reversing of the flow direction near the walls and flow separation. Since the divergence angle of a diffuser is limited in practice and is about 7 degrees, the process of flow distribution will involve a large portion of the tunnel circuit. Therefore, it is extremely important that the designed diffuser has a minimum length and a maximum angle of divergence, and yet, requirements related to appropriate recycling of pressure and lack of flow separation would be met [4].
Studies conducted on the effect of diffusers angle on flow conditions reveal that in a small expansion angle (total angle of 8 degrees), the flow profile is and stable and symmetrical. In a slightly larger angle (total angle of 10 degrees), the flow profiles becomes asymmetric, but still without backflow and instability. Thus, one can conclude that small expansion angles (up to 8 degrees) are the most appropriate expansion angles in diffusers. The dimensions of the tunnel diffuser in the above project, which is located after the test section, are shown in Table (6), the diffuser built in the water tunnel of the University is given in Figure (13).

Table 6. Dimensions of diffuser of the free surface tunnel built

\begin{tabular}{ccccc}
\hline \multirow{2}{*}{$\begin{array}{c}\text { Length } \\
{[\mathbf{m}]}\end{array}$} & \multicolumn{2}{c}{ Inlet } & \multicolumn{2}{c}{ Outlet } \\
\cline { 2 - 5 } & $\begin{array}{c}\text { Height } \\
{[\mathbf{m}]}\end{array}$ & $\begin{array}{c}\text { Width } \\
{[\mathbf{m}]}\end{array}$ & $\begin{array}{c}\text { Height } \\
{[\mathbf{m}]}\end{array}$ & $\begin{array}{c}\text { Width } \\
{[\mathbf{m}]}\end{array}$ \\
\hline 2.5 & 0.2 & 0.3 & 0.33 & 0.56 \\
\hline
\end{tabular}

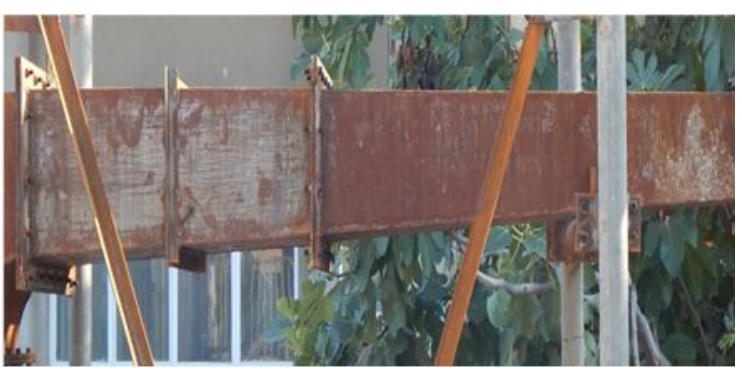

Figure 13. Diffiuser of water tunnel of Babol Noshirvani unversity of Technology

\subsection{Hydrodynamic design of settling chamber and the honeycomb}

Although the exact design of tunnel components located between the test and the nozzle sections reduce the level of turbulence, but in the water tunnel, it is necessary to use a settling chamber in the upstream of the converged part to reduce the level of turbulence and flow non-uniformities. Most flow corrective honeycombs are placed in the settling chamber to reduce disturbances of the flow up to the desired level. According to conducted tests, the length of the settling section should be at least about 2 to 3 times of the hydraulic diameter of the nozzle inlet duct. Given that there is no comprehensive theory in connection with the settling chambers in a form used in water tunnels, a reliable method to evaluate this component of the water tunnels is to study the settling chambers of the built water tunnels. Certainly, the built water tunnels, which have been used, have a good performance intended by their designers. Thus, investigating and studying them is a very suitable model for designing the settling chamber of the water tunnel in this project. In Figure (14), a number of tunnels investigated to obtain a suitable model to design the settling chamber have been given. 
a) Emerson Cavitation tunnel (England)

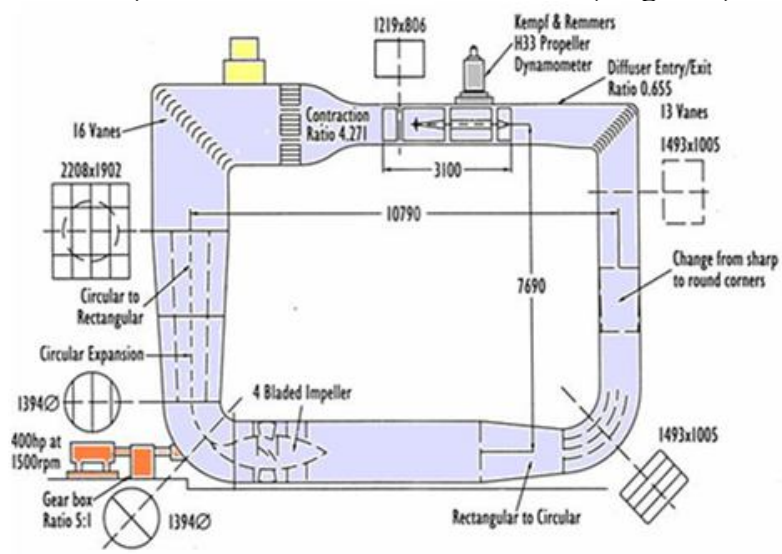

The approximate ratio of length to width of settling chamber $1: 1$

b) Cavitation tunnel (Netherland)

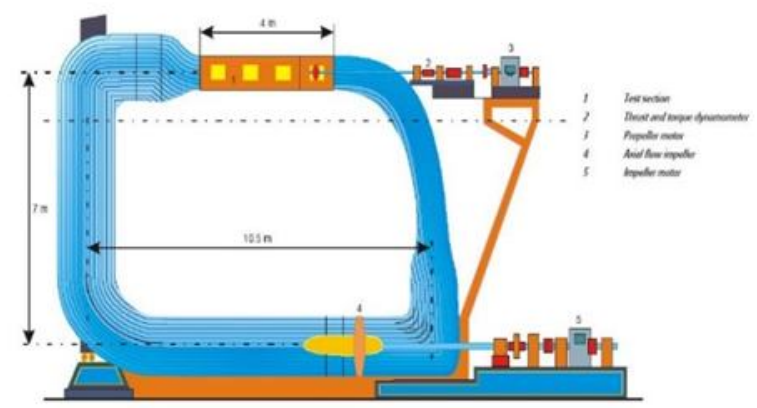

The approximate ratio of length to width of settling chamber $1: 1$

\section{c) Hykat HSAV cavitation tunnel (Germany)}

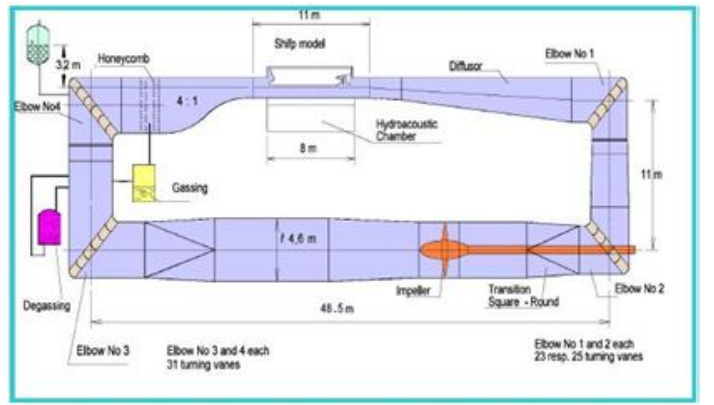

The approximate ratio of length to width of settling chamber 1.1:1.4

d) Samsung cavitation tunnel (South korea)

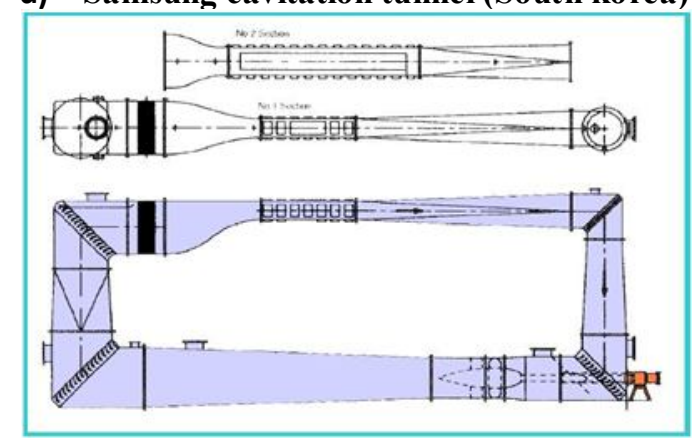

The approximate ratio of length to width of settling chamber $1: 1.5$

Figure 14. The approximate ratio of length to width of a number of tunnels built in the world
By examining the tunnels built in the world, it has been found in most tunnels, especially closed circuit tunnels, the ratio of length to width of the settling chamber is between 1 and 1.5. In this project, the ratio of length to the hydraulic diameter of the chamber is considered as 1.4. Two sets of grid and honeycomb are used to slow down the flow. The grid (lace) is as used as a turbulence lowering in wind tunnels. The honeycomb is used in the water tunnels to reduce turbulences and increase the uniformity of the fluid flow. An example of a honeycomb structure in a three-dimensional view is shown in Figure (15). Typically, the location of the honeycomb installation in water tunnels is immediately before the converging section (nozzle). In this project, the honeycomb occurs at a distance of $75 \mathrm{~cm}$ from the nozzle inlet.
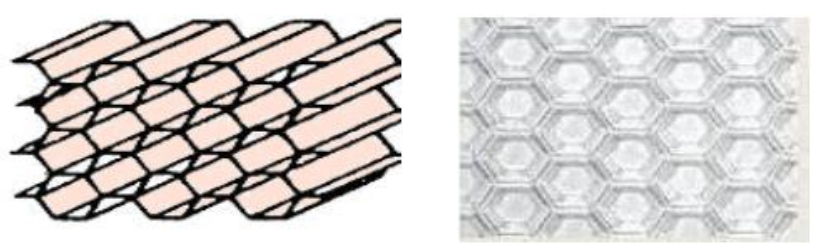

Figure 15. An example of a honeycomb structure in a threedimensional view

The profile of the settling chamber and the honeycomb are as seen in Table (7):

Table 7. Dimensions of settling chamber of the free surface tunnel built

\begin{tabular}{|c|c|c|c|c|}
\hline \multirow{2}{*}{$\begin{array}{l}\text { The ratio of } \\
\text { length of } \\
\text { chamber to } \\
\text { hydraulic } \\
\text { diameter [m] }\end{array}$} & \multirow{2}{*}{$\begin{array}{l}\text { Length of } \\
\text { settling } \\
\text { chamber } \\
{[\mathrm{m}]}\end{array}$} & \multicolumn{2}{|c|}{$\begin{array}{l}\text { Inlet and outlet } \\
\text { of settling } \\
\text { chamber }\end{array}$} & \multirow{2}{*}{$\begin{array}{c}\text { Distance of } \\
\text { honeycomb from } \\
\text { the inlet of } \\
\text { nozzle }[\mathrm{m}]\end{array}$} \\
\hline & & $\begin{array}{c}\text { Width } \\
\text { [m] }\end{array}$ & $\begin{array}{c}\text { Height } \\
\text { [m] }\end{array}$ & \\
\hline $1.4: 1$ & 1 & 0.6 & 0.9 & 0.75 \\
\hline
\end{tabular}

\subsection{Elbow and guide blades computations}

All the closed circuit tunnels have a few shifts or rotations of the flow circulation with a usual number of 4 . The elbow must be designed in such a way that would have a minimum energy loss and minimum disturbances in the speed uniformity. The guide blades are used to reduce the turbulence severity and reduce disparities in the elbows. The guide blades installed correctly can reduce the maximum flow velocity at the exit of the 90 degrees bent from twice as fast as the average speed to 1.2 times of the average speed. The guide blades reduce the pressure drop in turbulent flow in the sharp bends through two ways of directing the flow around the bent internal radius and preventing flow separation and vortex formation as well as dividing the flow into separate channels. The process of designing elbows and guide blades can be described in the form of as algorithm, as shown in Figure (16). 
In the present water tunnel, given that a pump has been used instead of the first elbow, the number of elbows for flow rotation and flow return to the test section is equal to 3. The section shape of the elbow (bent) in each water tunnel is a function of the section shape of other parts of the water tunnel. Since the section shape of the testing part, and subsequently, its nozzle are rectangular, the shape of the elbow section is also selected rectangular.

In Figure (16), the elbow, elbow schematic and the guide blades in the present water tunnel are shown.
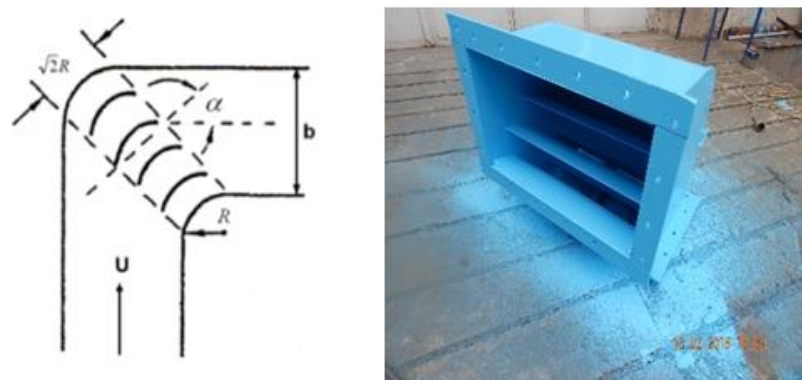

Figure 16. Elbow schematic and the guide blades of water tunnel of Babol Noshirvani unversity of Technology

\subsubsection{Elbow and guide blades computations}

Given the selection made according to the type of elbow as well as the type of guide blades used, the geometric parameters values are calculated [20] as follows:

A. Internal curvature radius (R)

In sharp bends, the ratio of internal curvature radius to the hydraulic diameter of duct is as $R / D<2$. Therefore, according to this equation, $\mathrm{R}$ is calculated as follows with the criteria of $R / D=0.42$.

\section{$B$. Length of the hypotenuse $(C)$}

The length of the blades' hypotenuse is calculated from the general relation (15) as follows:

$$
\mathrm{C}=2 \mathrm{R}_{i} \sin (\theta / 2)_{\theta=90}
$$

Where, $\mathrm{R}_{\mathrm{i}}, \theta$ are bent inner radius and elbow angle, respectively. For 90 degrees elbows: $C=\sqrt{2} R_{i}$

\section{Number of blades ( $n$ )}

For the case of same distance between short blades, the number of blades is calculated as follows:

$$
n=\alpha \frac{b}{R_{i}}-1
$$

Where, $b$ is width of the duct (ductal diameter for circular tubes). Also $\alpha$ is regardless of the elbow angle is 2.1 or 2.5

\section{Distance between the blades (d)}

The distance between the blades is calculated as follows:

$$
d=\frac{b \times \sqrt{2}}{n+1}
$$

In Figure (17), an initial view of the elbow and guide blades of the present water tunnel can be seen.

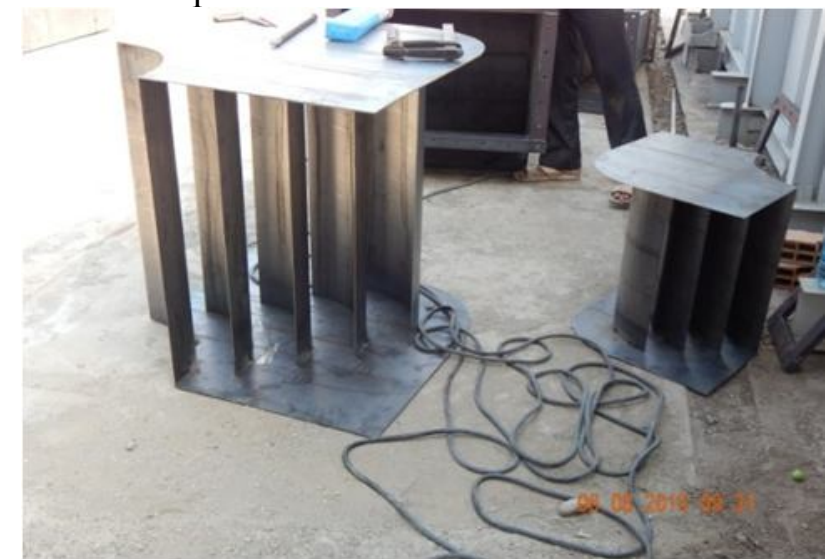

Figure 17. Initial view of the elbow and guide blades of the present water tunnel

\subsection{Calculating tunnel circuit losses}

To calculate losses in the closed circuit tunnel of the current project, the drops of all individual components used in the tunnel circuit must be calculated. Then, using these values, the circuit total loss will be calculated. To calculate the head in a horizontal duct, the relation $\mathrm{h}_{\mathrm{L}}=f \frac{l}{D} \frac{V^{2}}{2 g}$ is used. The minor losses in valves, gooseneck and honeycomb are calculated from $\mathrm{h}_{\mathrm{L}}=\mathrm{K}_{\mathrm{L}} \frac{V^{2}}{2 g}$ relation, where $f=\varphi\left(\operatorname{Re}, \frac{\varepsilon}{D}\right) \&$ $K_{L}=\varphi($ Geometry $)$.

According to local drops, the total drops of the water tunnel circuit (regardless of friction drops of the circuit compared with topical drops), respectively, including drops in the butterfly valve, stabilizer valve, 3 diffusers, 3 elbows, honeycomb and nozzle, was obtained in this project equal to $4.5 \mathrm{~m}$. considering the cross-section of the testing part and its maximum speed, the flow rate required was calculated for the selected pump as 300 (lit/s). After calculating the total loss amount of the closed circuit tunnel and required flow rate, a pump [21] with the following specifications was selected as shown in Table (8).

Table 8. Specifications of pump

\begin{tabular}{ccc}
$\begin{array}{c}\mathbf{Q} \\
{\left[\mathbf{m}^{\mathbf{3}} / \mathbf{m i n}\right]}\end{array}$ & $\mathbf{H}[\mathbf{m}]$ & $\begin{array}{c}\text { Engine } \\
\text { power }[\mathbf{h p}]\end{array}$ \\
\hline 1100 & 8 & 61 \\
\hline
\end{tabular}

\section{Tunnel profile}

The design of every single element of the tunnel provides the possibility that after connecting the parts, the overall profile of the tunnel would be specified. The tunnel specifications are respectively given in Table (9) and Figure 18. 
Table 9. Specifications of pump

\begin{tabular}{cc}
\hline $\begin{array}{c}\text { The total length of the tunnel } \\
\text { [m] }\end{array}$ & 8.7 \\
\hline $\begin{array}{c}\text { The total heigth of the tunnel } \\
\text { [m] }\end{array}$ & 3.25 \\
\hline \multirow{3}{*}{$\begin{array}{c}\text { Length [m] } \\
\text { West section }\end{array}$} & 2 \\
\cline { 2 - 2 } Width [m] & 0.3 \\
\hline $\begin{array}{c}\text { Maximum velocity in test } \\
\text { section [m/s] }\end{array}$ & 0.2 \\
\hline Q [1/s] & 5 \\
\hline RPM & 300 \\
\hline
\end{tabular}

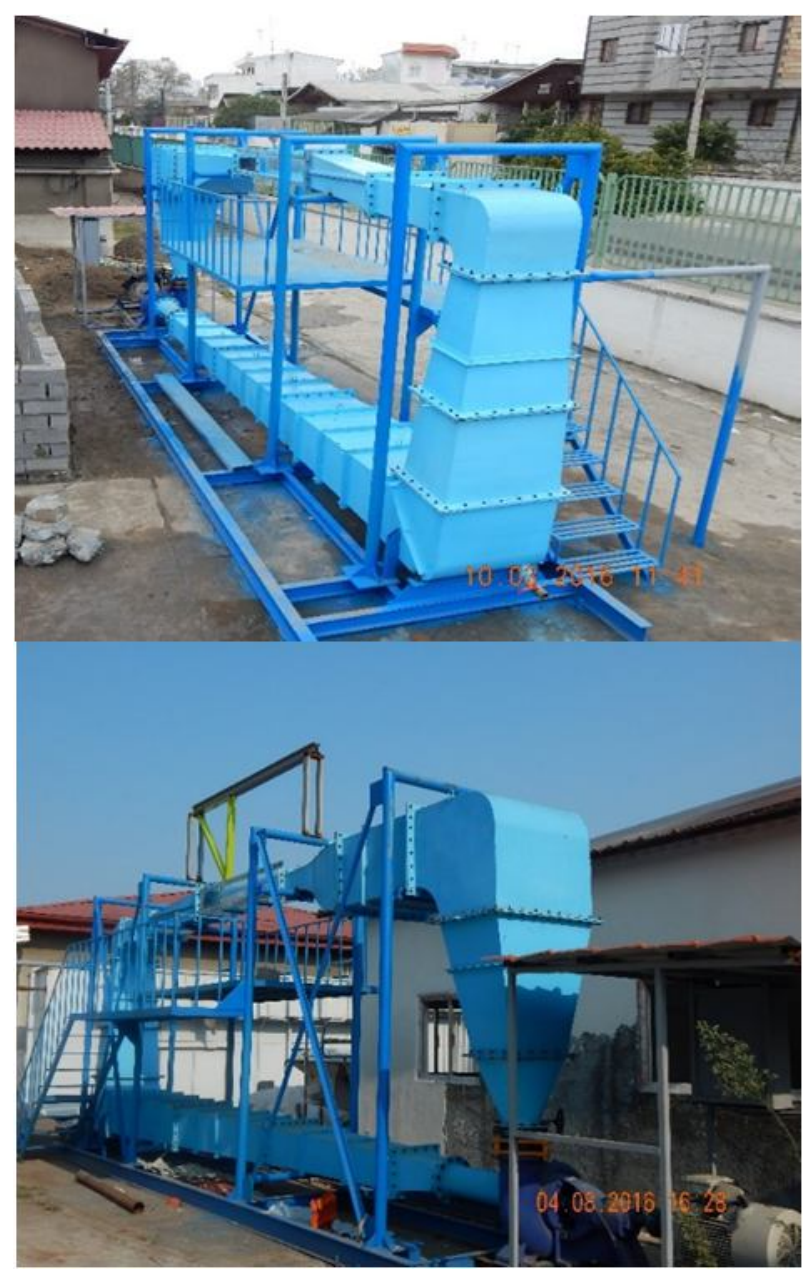

Figure 18. water tunnel built in Babol Noshirvani unversity of Technology

\section{Dynamometer}

Dynamometer is an important component of the tunnel designed to measure hydrodynamic forces on the spinning impeller. The dynamometer task is to transfer the engine force to the propeller and simultaneously measuring the thrust force and torque produced by the propeller. A dynamometer must be designed in such a way to be fit completely in the propeller hub. The propeller is fully protected by the dynamometer so that all forces and torque acting on the propeller would be transferred to the propeller through the dynamometer. In Figure (19), the placement of dynamometer in the test section is shown.
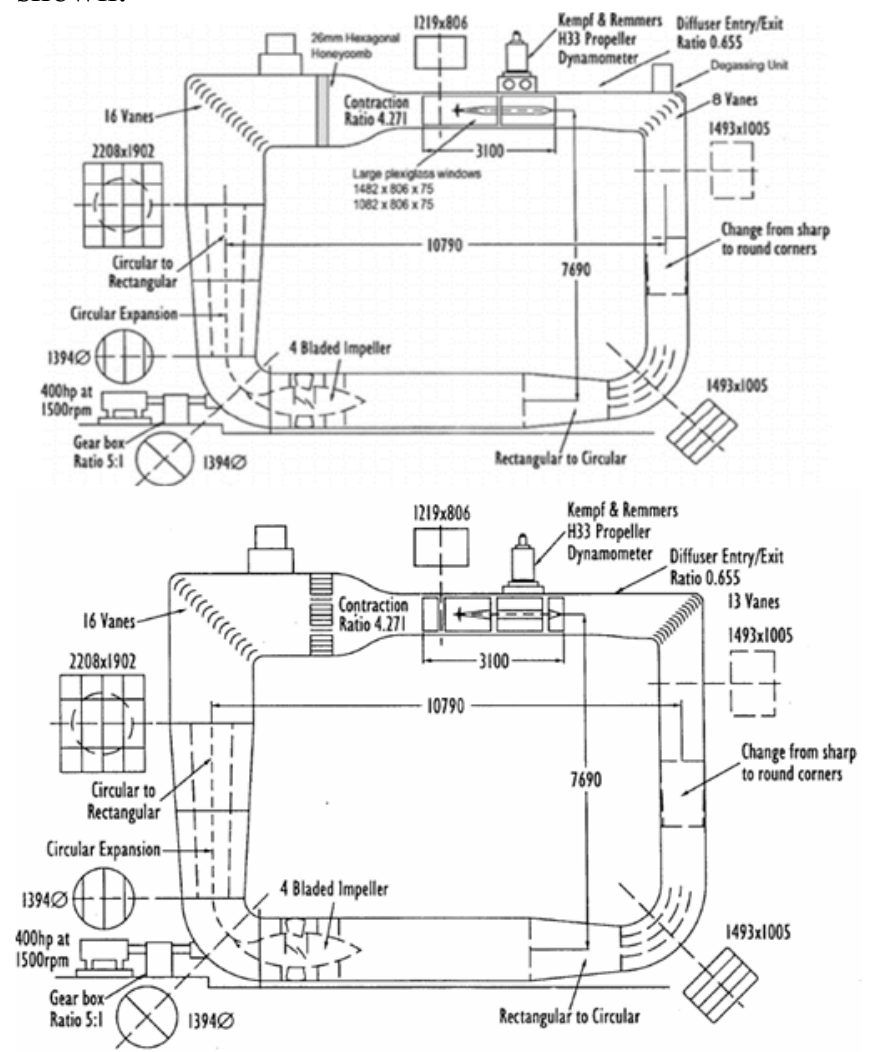

Figure 19. Kempf \& Remmers dynamometer of propeller at test section of emerson water tunnel

There are many problems in designing and making this type of dynamometers due to their multicomponent feature. In Figure (20), an example of dynamometer made by Cussons Company is shown.

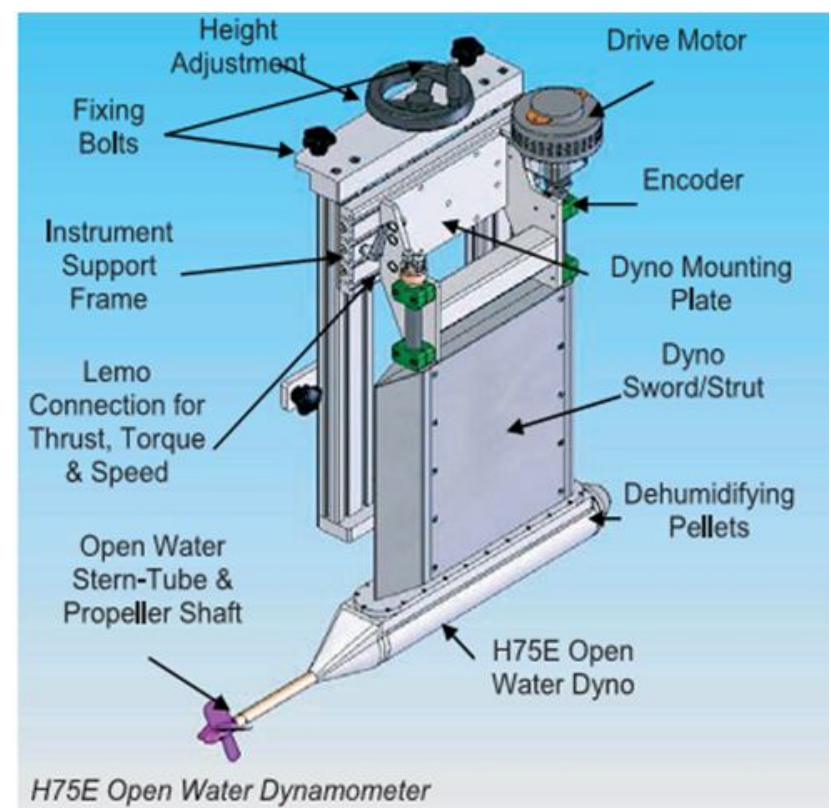

Figure 20. A dynamometer made by Cussons Company [22]

The two-component dynamometer designed by Seabased Energy Research Group, Babol Noshirvani unversity of Technology has the ability to measure torque and thrust forces at different angles of the shaft 
deflection, Yaw angle and immersion ratio. In Figure (21), the general schematic of the two-component dynamometer designed by Sea-based Energy Research Group, is shown to test the surface-piercing propeller in the free surface cavitation tunnel. This two-component dynamometer is capable of measuring thrust and torque forces at different angles of shaft deflection, angle of Yaw and immersion ratio.

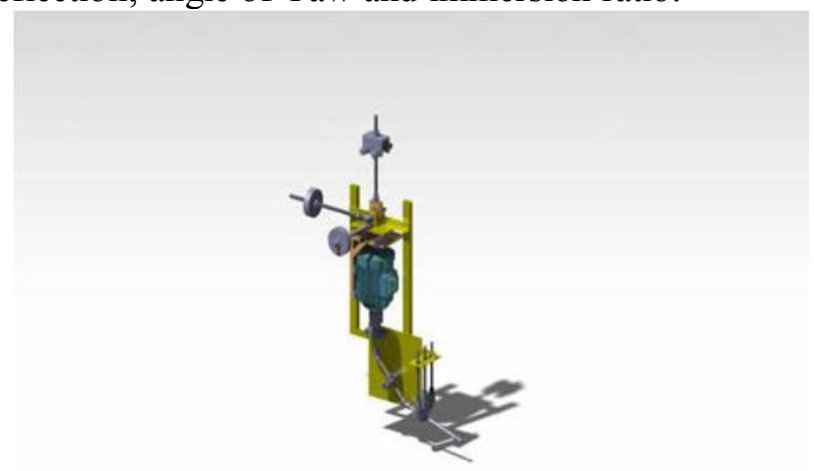

Figure 21. General schematic of the two-component dynamometer designed by Sea-based Energy Research Group

Figure (22) shows the dynamometer and propeller made that has been installed in the cavitation tunnel at test section. In order to validate cavitation tunnel design and dynamometer, final test was done on surface-piercing propeller with five blade and results has been compared with the results of ferrando' experimental test [6].
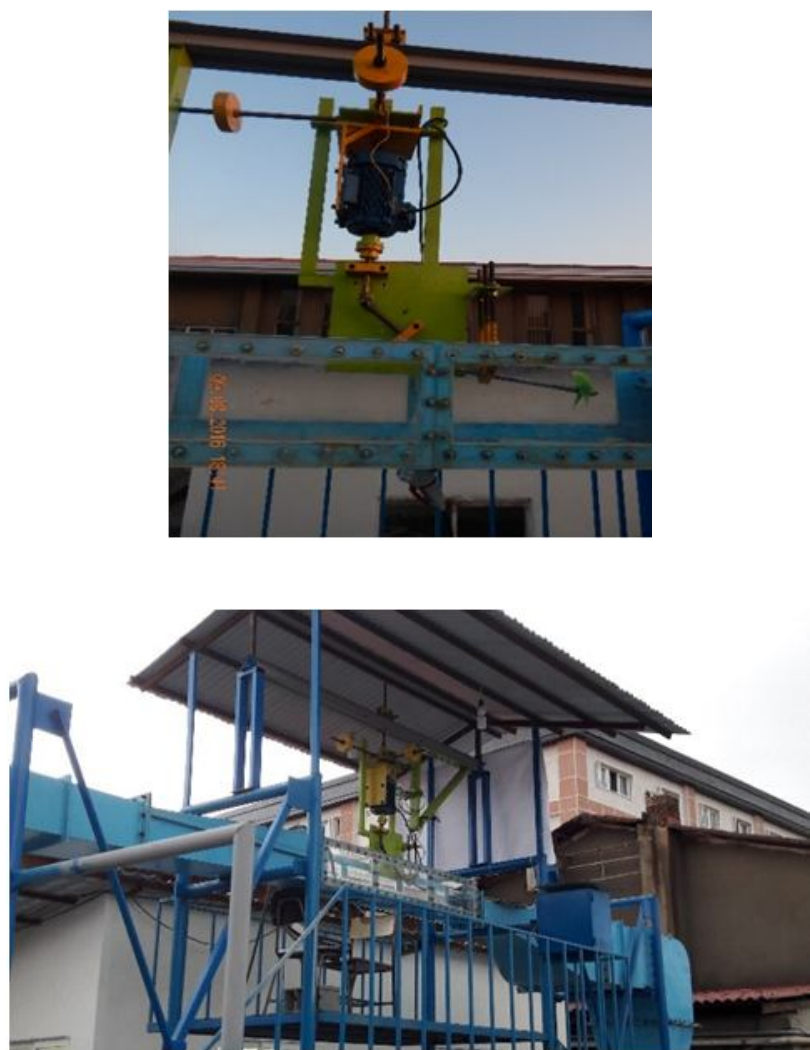
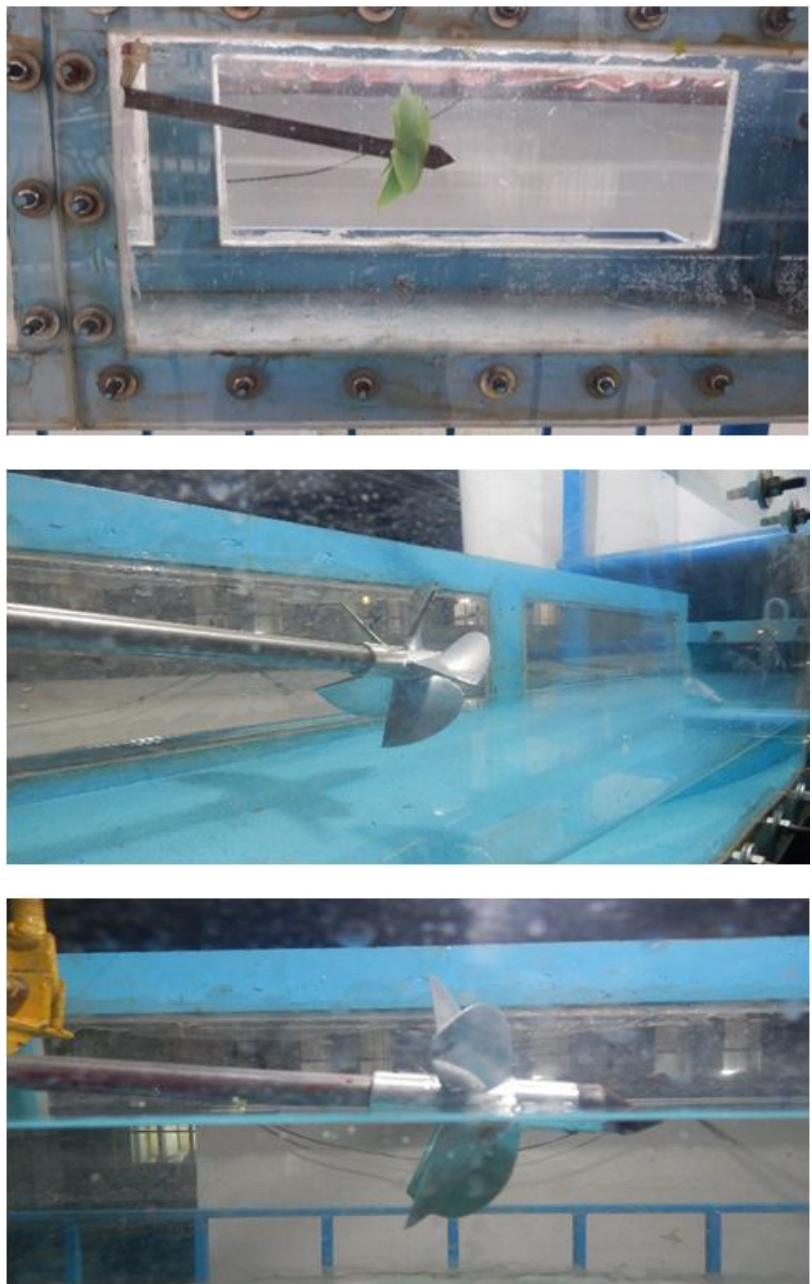

Figure 22. Dynamometer made that has been installed at test section

\section{Conclusion}

According to problems of theoretical methods for modeling of SPPs, the design of these propeller is done mainly based on empirical studies and model experiments. For examining and testing the propeller, a device is needed to do laboratory test. Water tunnel or free surface cavitation tunnel is one of the most important devices to conduct hydrodynamic experiments. In this paper, first, the calculations and construction of various components of a free surface closed circuit cavitation tunnel in the laboratory of hydrodynamics, acoustics and marine propulsion of Noshirvani University are provided. In the end, by assembling the components, a tunnel with a rectangular test section was obtained with length of 2 meters, width of 0.3 meters and height of $0.2 \mathrm{~m}$. also, the overall length of tunnel was calculated as 8.7 meters, and its height was designed as 3.25 meters. Finally, a two-component dynamometer was designed and built to measure thrust and torque forces exerted on the SPP.

\section{References}

1- Califano, A., (2010), Dynamic loads on marine propellers due to intermittent ventilation, Phd Thesis. 
2- Hadler, J., Hecker, R., (1968), Performance of partially submerged propellers, Proc 7th ONR Symposium on Naval Hydrodynamics, Rome.

3- Yin Lu Young, B.S., (2002), Numerical Modeling of Supercavitating and Surface-Piercing Propellers, Report No. 02-1 Thesis (Ph. D.), Department of civil engineering, The university of texas at austin, TX 78712, Environmental and water resourses engineering,

4- Yangajeh, M.A., Seif, M.S., Mehdigholi, H., (2009), Determination of propeller speed in experimental model of surface-piercing propeller, 11th international conference of iranian marine industries, kish island. (In Persian)

5- Montazeri, N., Ghassemi, H., Ditermination of hydrodynamic coefficients of surface-piercing propeller by regression method, 6th annual conference of design principles and applications of high speed craft, chaloos, iran. (In Persian)

6- Ferrando, M., Crotti, S., and Viviani, M., (2007), Performance of family of surface piercing propellers, Genova, Italy, pp. 63-70.

7- Carlton, J., (2012), Marine propellers and propulsio, Butterworth-Heinemann.

8- Mohammad Nouri, N., Kamran, M., Mostafapur, K., Bahadori, R., (2015), Design and fabrication of a force-moment measurement system for testing of the models in a water tunne, Modares mechanical engineering, Vol. 14, pp. 291-298. (In Persian)

9- https://www.marsys.tu-berlin.de/.../Flyer.

10-https://www.amc.edu.au/maritime-

engineering/cavitation-research-laboratory.

11- Borchert, S., Kroger, W., Hohne, S., Damaschke, N. S., Zhou, Z., (2012), ON OPTICAL QUANTIFICATION OF CAVITATION PROPERTIES", Proceedings of the Eighth International Symposium on Cavitation.

12- Van Lammeren, W. P. A., (1955), Testing Screw Propellers in a Cavitation Tunnel with Controllable Velocity Distribution over .the Screw Disk. Meeting of the New England Section of the society of Naval. Architect and marine engineering.

13- Aktasa, B., Atlara, M., Turkmena, S., Korkutb, E., Fitzsimmons, P., (2016), Systematic cavitation tunnel tests of a Propeller in uniform and inclined flow conditions as part of a round robin test campaign, Ocean Engineering, Vol. 120, No. 1, Page Number $136-151$.

14- Ferrando, M., Scamardella, A., (1996), Surface piercing propellers: Testing methodologies, results analysis and comments on open water characteristics, Proceedings: Small Craft Marine Engineering Resistance \& Propulsion Symposium.

15- Nozawa, K., Takayama, N., (2002), Experimental study on propulsive performance of surface piercing propeller, JOURNAL-KANSAI SOCIETY OF NAVAL ARCHITECTS JAPAN, Page Number 63 70.

16- Olofsson, N., Takayama, N., (1996), Force and flow characteristics of a partially submerged propeller, Chalmers University of Technology.

17- Ripken, J. F., (1951), Design Studies for a Closed-

Jet Water Tunnel. St. Anthony Falls Hydraulic

Laboratory, Retrieved from the University of Minnesota Digital Conservancy.

18- Sahini, D., (2004), WIND TUNNEL BLOCKAGE CORRECTIONS:A COMPUTATIONAL STUDY', Master Thesis, Texas Tech University.

19- Bell, J. H. and Mehta, R. D., (1989), Boundary Layer Prediction for Small Low Speed Contractions, AIAA Journal, Vol. 27, No. 3, Page Number $372-$ 374.

20- Henry, J. R., (1944), Design of power-plant installations pressure-loss characteristics of duct components, National Advisory Committee for Aeronautics, Advanced Restrioted Report.

21- http://www.pumpiran.org/e-catalog/.

22- K\&R Marine Hydrodynamics Division CUSSONS TECHNOLOGY LTD. 